\title{
Building workforce capacity for complex care coordination: a function analysis of workflow activity
}

\author{
Liza Heslop ${ }^{1 *}$, Rebecca Power ${ }^{2}$ and Kathryn Cranwell ${ }^{3}$
}

\begin{abstract}
Background: The care coordination workforce includes a range of clinicians who manage care for patients with multiple chronic conditions both within and outside a hospital, in the community, or in a patient's home. These patients require a multi-skilled approach to support complex care and social support needs as they are typically high users of health, community, and social services. In Australia, workforce structures have not kept pace with this new and emerging workforce. The aim of the study was to develop, map, and analyse workforce functions of a care coordination team.
\end{abstract}

Methods: Workflow modelling informed the development of an activity log that was used to collect workflow data in 2013 from care coordinators located within the care coordination service offered by a Local Health Network in Australia. The activity log comprised a detailed classification of care coordination functions based on two major categories - direct and indirect care. Direct care functions were grouped into eight domains. A descriptive quantitative investigation design was used for data analysis. The data was analysed using univariate descriptive statistics with results presented in tables and a figure.

Results: Care coordinators spent more time (70.9\%) on direct care than indirect care (29.1\%). Domains of direct care that occupied the most time relative to the 38 direct care functions were 'Assessment' (14.1\%),

'Documentation' (13.9\%), 'Travel time' (6.3\%), and 'Accepting/discussing referral' (5.7\%). 'Administration' formed a large component of indirect care functions (14.8\%), followed by 'Travel' (12.4\%). Sub-analyses of direct care by domains revealed that a group of designated 'core care coordination functions' contributed to $40.6 \%$ of direct care functions.

Conclusions: The modelling of care coordination functions and the descriptions of workflow activity support local development of care coordination capacity and workforce capability through extensive practice redesigns.

Keywords: Care coordination, Chronic disease management, Health care, Health workforce reform, Interprofessional teams, Workflow modelling

\section{Background}

Care coordination is an umbrella term used for a range of health care roles that offer seamless support to patients who have complex health care, community, and social support needs [1]. There is no one accepted definition of care coordination [2]; its implementation follows diverse rules, regulations, guidelines, and service models [3,4]. Despite it being a concept that requires clarification [5-7],

\footnotetext{
* Correspondence: liza.heslop@vu.edu.au

'College of Health and Biomedicine, Victoria University, PO Box 14428, Melbourne, VIC 8001, Australia

Full list of author information is available at the end of the article
}

health care organisations have increased investment in care coordination service models to improve health outcomes for patients with complex chronic care and social support needs and to reduce the burden and complications of hospital re-admissions. To meet the needs of this growing patient group, new care coordination roles that traverse generalist and specialist clinical roles have burgeoned. Care coordination workforce reform and innovation have been supported by international initiatives, particularly in the US, where most states have standards, guidelines, and state laws to determine who may provide such services, as well as credentialing and 
licensing requirements to ensure those recruited to the roles are qualified [8].

In Australia there is no statutory framework to govern the care coordination workforce; there are no professional guidelines, consistent care type definitions or business rules to support care coordination. Various care coordination service models reported within the Australian literature tend to have been initiated by, and form part of, the authorising environment of the Australian Primary Health Care (PHC) system. The models mostly involve, or are led by, general medical practitioners as part of General Practice clinics, Aboriginal Health Services and Medicare Locals $[9,10]$, while other models form part of the Australian Primary Mental Health Care system [11].

The current study focuses on a care coordination service which is administered by a Local Health Network (LHN) while also being part of a public hospital. LHNs provide public hospital services in Australia and can contain one or more hospitals as part of a business group, geographical area, or community; they receive activity-based and block funding under the National Health Reform Agreement [12]. Thus, the care coordination service does not sit under $\mathrm{PHC}$ or Home and Community Care funding models. For the purposes of setting the care coordination context for this study, care coordination is defined as the provision of 'non-admitted' health care and support services to patients with complex and chronic health care conditions, by a public hospital. 'Non-admitted' care is a classification of activity-based policy and funding in Australia and includes Tier 2 services provided by hospitals to patients who do not undergo formal admission and do not occupy a hospital bed [13]. All care coordination activities of the LHN, including staffing and expenditure, are mostly reported for inclusion in the national 'non-admitted' activity-based dataset; however, the national model is still being refined and tested with regard to 'non-admitted' services.

In order to improve service delivery and the continuity between service providers across regional partners in primary, community, and acute settings, and to relieve pressure on the region's acute in-patient hospital services, the LHN developed a vision and strategy to help shape a responsive care coordination model of service to meet the complex health care needs of the population it serves in the Western region of Melbourne, Australia. Care coordination designates services where providers and clients work closely together to achieve common patient-centred goals of care. It forms an integral part of the concept of care continuity where there can be incomplete knowledge of providers' actions to meet clients' goals of care [14].

Under the LHN model, care coordination requires that discharge planning links the primary and community care services that are delivered by an integrated interprofessional team consisting of allied health practitioners, nurses, and support workers. This collaborative approach ensures that patients' health care requirements are planned and delivered in a logical, connected, and timely manner. It may include activities traditionally classified as case management such as arranging additional services through sub-contracting or purchase of services, the maintenance of agreements between organisations, organising case conferences, and the active monitoring of patient care plans with due consideration to family circumstances. In this service, not all referrals arise from an inpatient admission.

The care coordination service model at the LHN includes five specialist care coordination services known as the Immediate Response Service, Hospital Admission Risk Program, Aged Care Assessment Service, Post-Acute Care service, and the community-based Transitional Care Program. The Hospital Admission Risk Program service has been reported to be an effective service integration model as it reduced demand for hospital admissions without incurring cost [15]. As an umbrella for services the LHN has, over time, attracted a substantive care coordination workforce providing generalist and specialist clinical and non-clinical roles. Despite this, internal care coordination workforce planning frameworks and mechanisms to build workforce capability were found to be insufficiently detailed. It was essential for the LHN to focus on developing high performing, interprofessional teams, capable of working flexibly across professional boundaries to optimise care management, care coordination, inter-sectorial linkages, and planning. In order to reconfigure care coordination roles and support those roles with general capability and career pathways, the LHN required information about the nature of interprofessional care coordination activity and the distribution of care coordinators' functions within the care coordination service.

The aim of this study was to map and analyse the workflow functions of an existing care coordination workforce whose sole role was within a care coordination service. All the functions and activities performed by the care coordination workforce were identified and mapped into a model or classification of care coordination workforce functions and the time taken for each activity according to function and domain was quantified.

\section{Methods \\ Design}

A descriptive quantitative design informed the overall approach to workflow function analysis. Workflow functions are all the tasks performed by care coordinators in a given day. Workflow modelling is a linear task-oriented approach that can be used to represent the day-to-day performance of workflow functions and to assist with work process redesign [16]. Conceptually, we have followed Davenport's 
[17] definition of workflow process as a specific ordering of work activities across time, with a beginning and an end. Workflow modelling designs with wide-ranging applications to many industries have been systematically researched and developed into a Workflow Elements Model to assist researchers determine elements implicit to applied workflow modelling [18]. The model provides various elements associated with different 'motivational' and 'methodological' orientations. This study adopts two elements from the model described as 'temporality', which relates to the relationships among routine tasks, and 'time study' where the analysis shows how much time individual functions or activities contribute to workflow [18].

Workflow modelling methods have been applied previously in health care studies to describe work patterns of personal care workers in nursing homes [19], the activity of dieticians [20], and the care coordination activity of primary care nurses [21]. They have been used to build workforce flexibility, productivity, and efficiency [22]; a Canadian workflow modelling study generated outcomes that were used to support nursing role restructure across 17 acute health sites in British Columbia [23]. This study applies workflow modelling methods to represent and describe the components of workflow functions of an interprofessional service providing complex care coordination.

\section{The setting}

The setting for this study is a LHN in Victoria, Australia a major regional public provider of acute and subacute health services throughout Western metropolitan Melbourne. The population of the Western region of Melbourne is approximately 823,400 people; it will be one of Australia's fastest growing areas with a predicted population growth of $23 \%$ by the end of 2021 relative to 2011 population levels [24]. The region has a high proportion of culturally and linguistically diverse communities where English may not be the first language and where the population comprises a higher burden of disease than national averages, combined with a high proportion of socio-economic disadvantage [25]. The LHN also delivers a comprehensive suite of medication support services, a range of community services supporting discharge, rehabilitation, and recovery, and programs offered in conjunction with community partners which support people with complex and chronic care needs.

The LHN's care coordination workforce comprises clinical staff from four health care disciplines - nurses, social workers, physiotherapists, and occupational therapists. In addition, the service includes one support worker designated as an allied health assistant. The breakdown of the total full-time equivalent staff of 87.15 for 2013 was: Nursing (professional) (53.5); Allied Health (30.25); Psychology/pharmacy (2.4); Allied Health Assistant (1).

\section{Participants}

Participants in the study comprised all care coordinators rostered on duty during a two-day period of data collection. The study received ethical approval from relevant human research ethics committees (Victoria University Human Research Ethics Committee \& Western Health Human Research Ethics Committee). Informed consent was obtained from all participants.

\section{Instrument activity log}

A workflow activity log with considerable detail of all the LHN's care coordination workforce functions was developed into a spreadsheet and used to collect data. Care coordination literature on care coordinators mandated work functions was sourced and reviewed to assist with the descriptions of direct care functions and the eight direct care function domains [26-28]. The resultant workflow classifications of care coordinators' functions were determined to suit the activity of the setting's context.

Development and pre-testing of the activity log was conducted at two levels. Firstly, a clinical reference group of care coordination clinicians assisted with the development and review of the activity log. The reference group comprised six senior clinicians who had five or more years' experience in care coordination. Secondly, ten care coordinators trialled the activity log onsite to ensure all components of workflow were captured. Results from the trial resulted in several modifications to the classification of functions and the activity log. The trial highlighted the need for adjustment to the initially proposed 15 minute data collection periods as care coordinators frequently switched between direct and indirect care functions, in periods under 15 minutes. In the trial, extensive efforts were made to ensure care coordinators were able to allocate a workflow process to each category in a consistent manner despite the fact that each workflow process can present differently in certain circumstances. These efforts resulted in a detailed spreadsheet - the activity log - that was used as the data collection tool.

Workflow functions listed on the activity log were classified into two major categories for recording. These were denoted as direct care (patient attributable), comprising 38 functions, and indirect care (non-patient attributable), comprising 24 functions. Direct care refers to care coordinators' workflow activities that specifically relate to meeting patients' needs. Indirect care refers to care coordinators' activities that focused on maintaining the environment in which care is delivered. The finetuning between these two categories was supported by the trial and clinical reference group review.

Comprehensive instructions and guidelines were given to each participant and field-based support was provided 
to ensure shared understandings of key terms and dependable data entry. Full descriptions of each function were provided to the participants to assist with accurate self-recordings in the activity log. Activity logs were collected for two consecutive days. There were 53 care coordinators rostered on duty over the two day period and a total of 106 logs were returned.

\section{Data collection, management, and analysis}

All care coordinators on duty for the two day period were provided with hard copies of the activity log in the spreadsheet format for recording their time against each function.

The data from the activity logs were loaded into a spreadsheet and were then analysed using SPPS Version 20.0 for univariate descriptive statistics. When recording workflow data, care coordinators largely accounted for their activity in 15 minute periods. When different functions occurred during the 15 minute period, these were recorded within 5 minute periods. Based on the raw data of all functions recorded, the total time recorded in minutes, the mean time recorded in minutes and standard deviation of the mean and the percentage of total time attributed to each function were calculated.

In order to improve data management for analysis, the clinical reference group and research team reviewed the preliminary analysis of data and further categorisation of direct care functions was undertaken. Direct care functions were noted to occupy more than two thirds of workflow activity, representing a large and clinically meaningful group of activity. All 38 direct care functions were classified into 8 major domains to represent key areas of direct care workflow, namely: 'Access', 'Assessment', 'Providing consultation', 'Arranging care', 'Contracting', 'Treatment', 'Preparation/administration', and 'Other'. For example, the functions designated as 'Active case finding', 'Accepting/discussing referral', and 'Prioritising patients' were categorised within the direct care function domain 'Access'. The domains are simply a subset to represent groupings of direct care functions. Some examples of indirect care functions include 'Administration', 'Timeout break', and 'Budget/financial'.

\section{Results}

The total number of functions recorded was $n_{1}=3,520$. Of these, 2,637 $\left(n_{2}\right)$ were direct care functions and 875 $\left(n_{3}\right)$ were indirect care functions. There were 8 missing functions $(0.2 \%)$. The total work time recorded over the two-day period was 54,540 minutes (90.9 hours). Comparisons between time expended on direct and indirect care functions (Table 1) shows the proportion of total time spent on direct care functions (70.9\%) was more than two thirds of the total time spent on indirect care functions (29.1\%).

Analysis of direct care functions (Table 2) reveals that the highest proportion of time for direct care activity, relative to all time spent on direct care activity, was spent on 'Assessment' (function 2.2, 14.1\%) and 'Documentation' (function 7.4, 13.9\%). The lowest proportion of time was spent on 'Patient complaints' (function 6.7, $0.05 \%$ ), followed by 'Working with interpreters' (function 7.1, 0.1\%), 'Diversion from admission' (function 6.2, $0.4 \%$ ), 'Equipment - prescription/provision' (function 6.4, 0.4\%), 'Liaison - Psychiatry' (function 4.2, 0.5\%), 'Negotiating/advocacy' (function 4.8, 0.5\%), and 'Handover' (function $4.7,0.5 \%$ ).

Within the direct care functions, variation (standard deviation; SD) for function duration was highest for 'Technical-clinical care' (function 6.8, SD = 70.3), 'Meeting (e.g., ward, unit)' (function 4.6, SD = 31.6), and 'Assessment - other specialised' (function 2.3, SD = 27.2) compared to the variation for all direct care functions $\left(\mathrm{n}_{2}=2,637\right) \mathrm{SD}=17.0$. For these direct care functions, the time spent by individual care coordinators varied greatly. Such variation may be attributed to differences within the five specialist care coordination services that make up the service and/or there may have been differences across the four professional groups. Those functions with the lowest variation (SD), excluding 'Patient complaints' and 'Working with interpreters' where only 2 and 4 functions were recorded, respectively, namely 'Follow-up call after discharge' (function 6.5, SD = 3.5), 'Handover' (function 4.7, SD = 4.1), and 'Liaison - Medical/ nursing staff' (function 4.1, SD = 5.3) may be considered to be more standardised and similar with regard to time expenditure.

Analysis of direct care functions by domain (Tables 3) reveals the 'Preparation/administration' function domain was the most time-consuming of all the function domains (26.8\%).

This is partly attributable to the high percentage of time recorded for 'Documentation' (13.9\%) within this

Table 1 Comparisons between direct and indirect care functions

\begin{tabular}{llll}
\hline Function & $\mathbf{n}_{\mathbf{1}}=\mathbf{3 , 5 2 0}$ & Total time (minutes) & $\begin{array}{l}\text { Mean time (minutes) } \\
\text { (standard deviation) }\end{array}$ \\
\hline Direct care & $\mathrm{n}_{2}=2,637$ & 38,695 & $14.6(17.0)$ \\
attributed to each function
\end{tabular}


Table 2 Descriptive analysis for direct care functions

\begin{tabular}{|c|c|c|c|c|c|c|c|}
\hline \multicolumn{2}{|c|}{$\begin{array}{l}\text { Function number and } \\
\text { name }\end{array}$} & \multirow{2}{*}{$\begin{array}{l}\text { Functions recorded } \\
\mathbf{n}_{2}=2637 \\
61\end{array}$} & \multirow{2}{*}{$\begin{array}{l}\begin{array}{l}\text { Total time } \\
\text { (minutes) }\end{array} \\
990\end{array}$} & \multicolumn{2}{|c|}{$\begin{array}{l}\text { Mean time (minutes) } \\
\text { (standard deviation) }\end{array}$} & \multirow{2}{*}{$\begin{array}{l}\text { Percentage of total } \\
\text { time attributed } \\
\text { to each function } \\
2.6 \%\end{array}$} & \multirow{2}{*}{$\begin{array}{l}\text { Rank of percentage o } \\
\text { total time attributed } \\
\text { to the function } \\
14\end{array}$} \\
\hline 1.1 & Active case finding & & & 16.2 & $(12.6)$ & & \\
\hline 1.2 & $\begin{array}{l}\text { Accepting/discussing } \\
\text { referral }\end{array}$ & 230 & 2,195 & 9.5 & $(6.2)$ & $5.7 \%$ & 4 \\
\hline 1.3 & Prioritising patients & 30 & 310 & 10.3 & $(6.1)$ & $0.8 \%$ & 28 \\
\hline 2.1 & Risk screening & 47 & 675 & 14.4 & $(10.0)$ & $1.7 \%$ & 19 \\
\hline 2.2 & Assessment & 209 & 5,440 & 26.0 & $(24.7)$ & $14.1 \%$ & 1 \\
\hline 2.3 & $\begin{array}{l}\text { Assessment - other } \\
\text { specialised }\end{array}$ & 47 & 1,390 & 29.6 & $(27.2)$ & $3.6 \%$ & 7 \\
\hline 3.1 & Community & 22 & 400 & 18.2 & $(18.9)$ & $1.0 \%$ & 26 \\
\hline 3.2 & Medical staff & 17 & 245 & 14.4 & $(14.4)$ & $0.6 \%$ & 31 \\
\hline 3.3 & Nursing staff & 35 & 635 & 18.1 & $(18.1)$ & $1.6 \%$ & 22 \\
\hline 3.4 & Other (comment) & 56 & 1,100 & 19.6 & $(20.3)$ & $2.8 \%$ & 12 \\
\hline 4.1 & $\begin{array}{l}\text { Liaison - Medical/ } \\
\text { nursing staff }\end{array}$ & 99 & 940 & 9.5 & $(5.3)$ & $2.4 \%$ & 16 \\
\hline 4.2 & Liaison - Psychiatry & 14 & 175 & 12.5 & $(8.4)$ & $0.5 \%$ & 32 \\
\hline 4.3 & $\begin{array}{l}\text { Liaison - Community } \\
\text { agencies }\end{array}$ & 72 & 745 & 10.3 & $(8.1)$ & $1.9 \%$ & 18 \\
\hline 4.4 & $\begin{array}{l}\text { Liaison - General } \\
\text { Practitioner }\end{array}$ & 23 & 265 & 11.5 & $(6.9)$ & $0.7 \%$ & 30 \\
\hline 4.5 & Liaison - Other & 111 & 1,050 & 9.5 & $(7.3)$ & $2.7 \%$ & 13 \\
\hline 4.6 & Meeting (e.g., ward, unit) & 27 & 1,475 & 54.6 & (31.6) & $3.8 \%$ & 6 \\
\hline 4.7 & Handover & 21 & 200 & 9.5 & $(4.1)$ & $0.5 \%$ & 33 \\
\hline 4.8 & Negotiating/advocacy & 19 & 195 & 10.3 & $(7.7)$ & $0.5 \%$ & 34 \\
\hline 4.9 & Patient monitoring & 105 & 1,170 & 11.1 & $(8.7)$ & $3.0 \%$ & 11 \\
\hline 4.10 & Referral - internal & 26 & 315 & 12.1 & $(9.7)$ & $0.8 \%$ & 29 \\
\hline 4.11 & Referral - external & 102 & 1,260 & 12.4 & $(9.1)$ & $3.3 \%$ & 9 \\
\hline 5.1 & $\begin{array}{l}\text { Contracting/liaising with } \\
\text { provider - internal }\end{array}$ & 65 & 495 & 7.6 & $(4.7)$ & $1.3 \%$ & 25 \\
\hline 5.2 & $\begin{array}{l}\text { Contracting/liaising with } \\
\text { provider - external }\end{array}$ & 192 & 1,560 & 8.1 & $(11.7)$ & $4.0 \%$ & 5 \\
\hline 6.1 & Education & 80 & 1,310 & 16.4 & $(17.0)$ & $3.4 \%$ & 8 \\
\hline 6.2 & $\begin{array}{l}\text { Diversion from } \\
\text { admission }\end{array}$ & 17 & 150 & 8.8 & $(7.4)$ & $0.4 \%$ & 35 \\
\hline 6.3 & $\begin{array}{l}\text { Counselling /health } \\
\text { coaching }\end{array}$ & 42 & 665 & 15.8 & $(8.1)$ & $1.7 \%$ & 20 \\
\hline 6.4 & $\begin{array}{l}\text { Equipment - prescription/ } \\
\text { provision }\end{array}$ & 9 & 160 & 17.8 & $(7.9)$ & $0.4 \%$ & 36 \\
\hline 6.5 & $\begin{array}{l}\text { Follow-up call after } \\
\text { discharge }\end{array}$ & 47 & 340 & 7.2 & (3.5) & $0.9 \%$ & 27 \\
\hline 6.6 & Carer support & 43 & 580 & 13.5 & $(7.7)$ & $1.5 \%$ & 23 \\
\hline 6.7 & Patient complaints & 2 & 20 & 10.0 & $(0.0)$ & $0.05 \%$ & 38 \\
\hline 6.8 & Technical-clinical care & 25 & 915 & 36.6 & $(70.3)$ & $2.4 \%$ & 17 \\
\hline 7.1 & $\begin{array}{l}\text { Working with } \\
\text { interpreters }\end{array}$ & 4 & 50 & 12.5 & $(2.8)$ & $0.1 \%$ & 37 \\
\hline 7.2 & $\begin{array}{l}\text { Reading medical } \\
\text { history/report }\end{array}$ & 92 & 1,285 & 14.0 & $(10.0)$ & $3.3 \%$ & 10 \\
\hline 7.3 & Background research & 52 & 655 & 12.6 & $(9.4)$ & $1.7 \%$ & 21 \\
\hline
\end{tabular}


Table 2 Descriptive analysis for direct care functions (Continued)

\begin{tabular}{|c|c|c|c|c|c|c|c|}
\hline 7.4 & Documentation & 353 & 5,380 & 15.2 & $(16.9)$ & $13.9 \%$ & 2 \\
\hline 7.5 & Set up/clean up & 36 & 585 & 16.3 & $(18.2)$ & $1.5 \%$ & 24 \\
\hline 7.6 & $\begin{array}{l}\text { Travel time (including } \\
\text { walking) }\end{array}$ & 129 & 2,420 & 18.8 & $(10.9)$ & $6.3 \%$ & 3 \\
\hline 8.1 & Other (comment) & 76 & 955 & 12.6 & $(17.9)$ & $2.5 \%$ & 15 \\
\hline Total & & 2637 & 38,695 & 14.6 & $(17.0)$ & $100.0 \%$ & \\
\hline
\end{tabular}

domain (Table 2). The function domains of 'Arranging care' (20.1\%) and 'Assessment' (19.4\%) also required significant time expenditure. Analysis of indirect care functions (Table 4), excluding 'Time-out break' and 'Time completing the activity log, shows the most time-consuming functions were 'Administration' (14.8\%), 'Travel' (12.4\%), and 'Meetings' (8.0\%).

\section{Sub-analyses of selected domains of direct care activity}

Three groupings of direct care domains were also established by the clinical reference group and research team. This was done in order to represent the data in an administratively meaningful way. These groups were designated 'Assessment and treatment', 'Clinical administration', and 'Core care coordination functions'. The group 'Assessment and treatment' included direct care domain numbers 2 and 6 ('Assessment' and 'Treatment'), 'Clinical Administration' included the domain numbers 7 and 8 ('Preparation/ Administration' and 'Other'), and 'Core care coordination functions' included direct care domain numbers 1, 3, 4, and 5 ('Access', 'Providing Consultation', 'Arranging Care', and 'Contracting').

'Core care coordination functions' were shown to contribute more to overall function time durations than the other two groups 'Assessment and treatment' and 'Clinical Administration' (40.6\% vs. $30.1 \%$ and $29.3 \%$, respectively; Table 5).

Figure 1 depicts the box plots of time duration for these three groups using interquartile ranges. Note that the 25th percentile is equal to the minimum categorical values of time duration where the minimum duration recorded was 5 minutes. As illustrated in Figure 1, there is a smaller interquartile range for 'Core care coordination functions' and 'Clinical administration' (Q3 - Q1 = 15 $5=10$ minutes), respectively, versus 'Assessment and treatment' (Q3 - Q1 = 25 - 5=20 minutes). Consistent with the above observation, the group 'Core care coordination functions' has less variation of function time duration ( $\mathrm{SD}=12.8)$ in comparison to 'Clinical administration' $(\mathrm{SD}=15.1)$ and 'Assessment and treatment' $(\mathrm{SD}=24.8)$. The smaller SD value for functions implies that these functions have less time duration variations; hence, these functions are more stable and predictable in time required even when performed by staff in different situations and across different services and professional groups.

\section{Discussion}

To our knowledge, there is no descriptive quantitative care coordination workflow process study available based on an interprofessional workforce providing services for patients with chronic illness and complex needs. Further, there are no studies available using workflow modelling to enable reliable comparisons in the interprofessional context we have described. The field of care coordination has been described as 'immature' because of the inherent challenges around building consensus on 'what constitutes care coordination', as well as the need to advance the systematic study of care coordination to build an evidence base inclusive of care coordination measurement [3]. Published studies that share some similarities to the methods of the current study include a US observational study of the work activity of ten primary care nurses undertaken to help understand the roles and tasks carried out by nurses in primary care, reporting that only $15 \%$ of total nurse work activity was 'care coordination' [21]. Findings from a health care workflow study undertaken with dieticians in three Australian hospitals which investigated designated workflow categories of direct and indirect care revealed the percentage of time spent on direct and indirect patient support activities was $18.3 \%$ and $40.4 \%$, respectively [20]. In contrast, our results show that direct care functions occupied more than two thirds of all care coordination activity in the context we studied.

Despite the emerging landscape concerning the science of care coordination, research has clarified and determined key concepts about workflow processes of interprofessional care which are also very dependent on context. An Australian study that more or less sits within the general practice model mentioned previously [9], offers a qualitative investigation into core processes that define the work of care coordinators, illuminating understandings of care coordination and its unique features for this context [29]. Participants were care coordinators comprising ten general practitioners and six registered nurses who delivered care coordination as members of a general practice team. Thematic analysis of participants' interviews revealed four distinguishing themes: 'moving beyond usual practice by spanning boundaries'; 'relationship-based care'; 'agreed roles and routines 
Table 3 Descriptive analysis of direct care functions by domain

\begin{tabular}{|c|c|c|c|c|c|c|}
\hline \multicolumn{2}{|c|}{$\begin{array}{l}\text { Function domain number } \\
\text { and name }\end{array}$} & \multirow{2}{*}{$\begin{array}{l}\text { Functions recorded } \\
\mathrm{n}_{\mathbf{2}}=\mathbf{2 , 6 3 7} \\
321\end{array}$} & \multirow{2}{*}{$\begin{array}{l}\begin{array}{l}\text { Total time } \\
\text { (minutes) }\end{array} \\
3,495\end{array}$} & \multicolumn{2}{|c|}{$\begin{array}{l}\text { Mean time (minutes) } \\
\text { (standard deviation) }\end{array}$} & \multirow{2}{*}{$\begin{array}{l}\text { Percentage of total time attributed } \\
\text { to each function domain } \\
9.0 \%\end{array}$} \\
\hline 1 & Access & & & 10.9 & $(8.2)$ & \\
\hline 2 & Assessment & 303 & 7,505 & 24.8 & $(23.8)$ & $19.4 \%$ \\
\hline 3 & Providing consultation & 130 & 2,380 & 18.3 & $(18.7)$ & $6.2 \%$ \\
\hline 4 & Arranging care & 619 & 7,790 & 12.6 & $(13.4)$ & $20.1 \%$ \\
\hline 5 & Contracting & 257 & 2,055 & 8.0 & $(10.4)$ & $5.3 \%$ \\
\hline 6 & Treatment & 265 & 4,140 & 15.6 & $(24.9)$ & $10.7 \%$ \\
\hline 7 & Preparation/administration & 666 & 10,375 & 15.6 & $(14.7)$ & $26.8 \%$ \\
\hline 8 & Other & 76 & 955 & 12.6 & $(17.9)$ & $2.5 \%$ \\
\hline \multicolumn{2}{|c|}{ Total } & 2,637 & 38,695 & 14.6 & $(17.0)$ & $100.0 \%$ \\
\hline
\end{tabular}

\section{Direct care domain}

1. Access

2. Assessment

4. Arranging care

5. Contracting

6. Treatment

7. Preparation/administration

\section{Function and number}

Active case finding 1.1

Accepting/discussing referral $\quad 1.2$

Prioritising patients $\quad 1.3$

Risk screening 2.1

Assessment 2.2

Assessment - other specialised 2.3

Community 3.1

Medical staff $\quad 3.2$

Nursing staff $\quad 3.3$

Other (comment) 3.4

Liaison - Medical/nursing staff $\quad 4.1$

Liaison - Psychiatry $\quad 4.2$

Liaison - Community agencies $\quad 4.3$

Liaison - General Practitioner $\quad 4.4$

Liaison - Other $\quad 4.5$

Meeting (e.g., ward, unit) $\quad 4.6$

Handover 4.7

Negotiating/advocacy $\quad 4.8$

Patient monitoring $\quad 4.9$

Referral - internal $\quad 4.10$

Referral - external 4.11

Contracting/liaising with provider - internal 5.1

Contracting/liaising with provider - external $\quad 5.2$

Education 6.1

Diversion from admission 6.2

Counselling/health coaching 6.3

Equipment - prescription/provision 6.4

Follow-up call after discharge $\quad 6.5$

Carer support 6.6

Patient complaints $\quad 6.7$

Technical-clinical care $\quad 6.8$

Working with interpreters $\quad 7.1$

Reading medical history/report $\quad 7.2$ 
Table 3 Descriptive analysis of direct care functions by domain (Continued)

\begin{tabular}{|c|c|c|}
\hline & Background research & 7.3 \\
\hline & Documentation & 7.4 \\
\hline & Set up/clean up & 7.5 \\
\hline & Travel time (including walking) & 7.6 \\
\hline 8. Other & Other (comment) & 8.1 \\
\hline
\end{tabular}

among relevant parties'; and 'committing to chronic condition care coordination' [29]. The study points to attributes and relational features of care coordination involving multiple disciplines and stakeholder groups. The concept of 'relational processes' in care coordination that involve complementary roles of each professional and their interdependencies have been identified as important processes in emerging interprofessional teams where the building of 'relational coordination' may ensure team functioning based upon shared goals, shared knowledge, and mutual respect [30].
Study limitations, strengths, and future research

This study was based upon a service model of care coordination where the context itself and the interactions between the contextual elements, the interprofessional configuration, and work functions are unique. Still, the service model does share similarities with international strategies and developments in care coordination models where non-physician providers are leading interprofessional team-based models to support care coordination in health systems [5]. Even so, differences in work functions according to context suggests that direct

Table 4 Descriptive analysis of indirect care functions

\begin{tabular}{|c|c|c|c|c|c|c|c|}
\hline \multicolumn{2}{|c|}{ Function number and name } & \multirow{2}{*}{$\begin{array}{l}\begin{array}{l}\text { Functions } \\
\text { recorded } \\
\mathbf{n}_{\mathbf{3}}=\mathbf{8 7 5}\end{array} \\
194\end{array}$} & \multirow{2}{*}{$\begin{array}{l}\begin{array}{l}\text { Total time } \\
\text { (minutes) }\end{array} \\
2,350\end{array}$} & \multicolumn{2}{|c|}{$\begin{array}{l}\text { Mean time (minutes) } \\
\text { (standard deviation) }\end{array}$} & \multirow{2}{*}{$\begin{array}{l}\text { Percentage of total time } \\
\text { attributed to each function }\end{array}$} & \multirow{2}{*}{$\begin{array}{l}\text { Rank of percentage of } \\
\text { total time attributed } \\
\text { to the function } \\
2\end{array}$} \\
\hline 1 & Administration & & & 12.1 & $(8.2)$ & & \\
\hline 2 & Time-out break & 164 & 3,290 & 20.1 & $(11.8)$ & $20.8 \%$ & 1 \\
\hline 3 & Budget/financial & 1 & 20 & 20.0 & $(0.0)$ & $0.1 \%$ & 22 \\
\hline 4 & Consultation (non-clinical) & 39 & 405 & 10.4 & (5.6) & $2.6 \%$ & 9 \\
\hline 5 & $\begin{array}{l}\text { Human resources, e.g., } \\
\text { appraisal, staff support }\end{array}$ & 4 & 110 & 27.5 & $(15.5)$ & $0.7 \%$ & 17 \\
\hline 6 & Human resources - Recruitment & 0 & 0 & 0.0 & $(0.0)$ & $0.0 \%$ & Not ranked \\
\hline 7 & Informal discussion with peers & 35 & 380 & 10.9 & (5.4) & $2.4 \%$ & 10 \\
\hline 8 & Meetings & 41 & 1,260 & 30.7 & $(21.9)$ & $8.0 \%$ & 5 \\
\hline 9 & Orientation & 3 & 95 & 31.7 & $(12.5)$ & $0.6 \%$ & 19 \\
\hline 10 & Planning & 38 & 980 & 25.8 & $(34.3)$ & $6.2 \%$ & 6 \\
\hline 11 & Presentations/inservices & 0 & 0 & 0.0 & $(0.0)$ & $0.0 \%$ & Not ranked \\
\hline 12 & Professional development & 7 & 240 & 34.3 & $(20.2)$ & $1.5 \%$ & 13 \\
\hline 13 & Quality improvement activity & 21 & 865 & 41.2 & $(38.2)$ & $5.5 \%$ & 7 \\
\hline 14 & Report writing/evaluation & 4 & 135 & 33.8 & $(18.8)$ & $0.9 \%$ & 16 \\
\hline 15 & Research & 7 & 110 & 15.7 & $(6.0)$ & $0.7 \%$ & 18 \\
\hline 16 & Rostering/work allocation & 11 & 365 & 33.2 & $(27.5)$ & $2.3 \%$ & 11 \\
\hline 17 & Service development & 2 & 85 & 42.5 & $(24.7)$ & $0.5 \%$ & 20 \\
\hline 18 & Statistics & 35 & 665 & 19.0 & $(14.6)$ & $4.2 \%$ & 8 \\
\hline 19 & Supervision/mentoring (provider) & 11 & 225 & 20.5 & $(10.5)$ & $1.4 \%$ & 14 \\
\hline 20 & Supervision/mentoring (recipient) & 2 & 35 & 17.5 & $(17.6)$ & $0.2 \%$ & 21 \\
\hline 21 & Teaching (students) & 12 & 160 & 13.3 & (9.3) & $1.0 \%$ & 15 \\
\hline 22 & Time completing the activity log & 127 & 1,810 & 14.3 & $(11.2)$ & $11.4 \%$ & 4 \\
\hline 23 & Travel (including walking) & 96 & 1,960 & 20.4 & $(11.6)$ & $12.40 \%$ & 3 \\
\hline 24 & Other & 21 & 300 & 14.3 & $(13.5)$ & $1.9 \%$ & 12 \\
\hline \multicolumn{2}{|c|}{ Total } & 875 & 15,845 & 18.1 & $(16.1)$ & $100.0 \%$ & \\
\hline
\end{tabular}


Table 5 Sub-analysis of direct care domain groupings

\begin{tabular}{|c|c|c|}
\hline Domain Group & Domain & $\begin{array}{l}\text { Percentage of total } \\
\text { time attributed to } \\
\text { each function domain }\end{array}$ \\
\hline \multirow{2}{*}{$\begin{array}{l}\text { Assessment and } \\
\text { treatment }\end{array}$} & Assessment & $19.4 \%$ \\
\hline & Treatment & $10.7 \%$ \\
\hline (Total for group) & & $(30.1 \%)$ \\
\hline \multirow[t]{2}{*}{ Clinical administration } & $\begin{array}{l}\text { Preparation/ } \\
\text { administration }\end{array}$ & $26.8 \%$ \\
\hline & Other & $2.5 \%$ \\
\hline (Total for group) & & $(29.3 \%)$ \\
\hline \multirow{4}{*}{$\begin{array}{l}\text { Core care coordination } \\
\text { functions }\end{array}$} & Access & $9.0 \%$ \\
\hline & Providing consultation & $6.2 \%$ \\
\hline & Arranging care & $20.1 \%$ \\
\hline & Contracting & $5.3 \%$ \\
\hline \multicolumn{2}{|l|}{ (Total for group) } & $(40.6 \%)$ \\
\hline \multicolumn{2}{|c|}{ Total time for direct care functions } & $100 \%$ \\
\hline
\end{tabular}

application of the classification proposed in this study to a range of care coordination models, particularly in PHC, may not be suitable. Another limitation is the modest two-day sampling, though every effort was made within research procedures to ensure accuracy of data entry to enable contextually-reliable results, it is possible for some misrepresentation of functions to have occurred.
The strengths of this study lie in the development and granularity of the data collection instrument that offers a foundation for LHN care coordination workflow classification and the collation and description of a large number of workflow functions depicting all activity of a care coordination workforce. Knowledge of the inherent activity of this workforce and the amount of time spent on different workflow functions provides a robust evidencebased resource for policy development concerning interprofessional service approaches. Measures of workflow functions captured in this study will be useful to Australian policy officials to support refinement and development of future revisions to the counting and funding rules for Tier 2 non-admitted services. Workflow function variables have been based on the type of clinician providing the service which can differentiate one aspect of resource utilisation for non-admitted services. Nevertheless, workflow must be considered as a dynamic process and some of the functions explicated in the instrument had very short time duration. This suggests the need for further research to refine and test the classifications used in the study's instrument. Further research may be generated from this study to estimate costs associated with conducting care coordination activity, including cross-service comparisons. Future research must also consider the impact of interprofessional workforce models on clinical and economic outcomes.

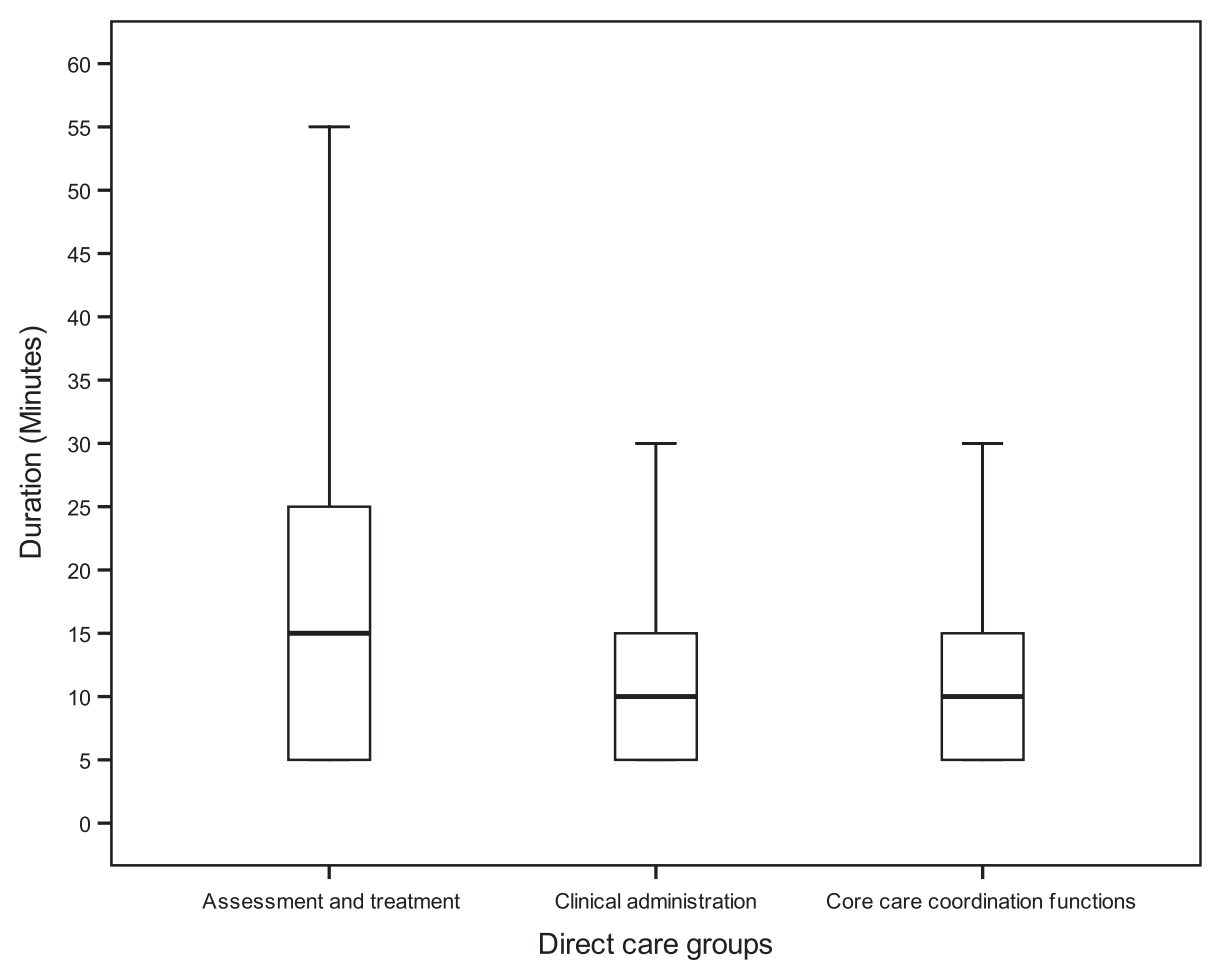

Figure 1 Box plots for time duration for three groups of direct care functions. 


\section{Conclusions}

The capacity of this LHN to provide high quality care coordination services to the rapidly expanding Western region of Melbourne, Australia, where the risks associated with low health and literacy levels are coupled with a high proportion of chronic illness, has unquestionably required prompt and effective innovation to develop capability and efficiency of a care coordination workforce. The findings of this study have provided valuable baseline descriptive workforce information about the workflow activity of the LHN's care coordination workforce that is supporting ongoing organised workforce reform and from which future change to this workforce can be monitored. The reform strategies currently in progress include care coordination role reconfiguration with unique fit-for-purpose roles and defined career pathways. The care coordination workforce reform vision, currently being enacted, is to improve the balance between specialist and generalist roles, establish specialist generalist roles with expanded scopes of practice, develop standards, tools, and protocols, and education and training.

In Australia, national activity-based funding policies are being developed to support multi-disciplinary 'clinic' models that currently fit within the Australian Tier 2 non-admitted care framework [31]. As high volumes of non-admitted services are provided in Australia, the Independent Hospital Pricing Authority intends to progress, in the longer term, the development of a 'non-admitted services' classification that can support activity-based funding [31]. Activity-based policy concerning funding and performance for 'non-admitted services' may be improved with the understanding of care coordination activities that this paper has offered. Multidisciplinary care models of a 'clinic' service may not be appropriately developed in the existing Australian nonadmitted Tier 2 classifications system. Given the expected growth in usage of non-admitted care services, further analysis of care coordination service activity deserves attention. Managers of health services may also consider options for building workforce capacity to manage chronic and complex illness, where roles can be configured within non-admitted services that may not necessarily be dependent on physician stewardship but where nurses and allied health professionals as nonphysician providers play a central role. Policy approaches that create operational partnerships between LHNs, community-based health services, and PHC services are needed to better deliver services to patients with the most complex health care needs.

\section{Abbreviations}

LHN: Local Health Network; PHC: Primary Health Care.

\section{Competing interests}

The authors declare that they have no competing interests.

\section{Authors' contributions}

LH carried out the literature review and ethical approvals and had oversight for the overall design, data analysis, presentation of data and interpretation, and led the drafting of and revisions to the manuscript. RP secured partial funding and was responsible for the initial design of the data collection instrument. RP also contributed to data interpretation and critical revision of the manuscript for important intellectual content. KC contributed to instrument development, data collection, data interpretation, and revision of drafts of the manuscript critically for important intellectual content. All authors read and approved the final manuscript.

\section{Acknowledgements}

Abby Bean and Prue Deckert from Western Health, Victoria, Australia, provided general support to the research team and assisted with development of the instrument and data analysis interpretation. Mahdi Bazargani, doctoral candidate from Victoria University, Australia, assisted with data entry and statistical analysis. Dr Sai Lu and Dr Charles Lawoko from Victoria University helped to refine statistical procedures. Professor Maximilian de Courten from Victoria University provided critical commentary. This study was supported with funding made available by Health Workforce Australia and Victoria University, Australia.

\section{Author details}

${ }^{1}$ College of Health and Biomedicine, Victoria University, PO Box 14428, Melbourne, VIC 8001, Australia. '2Strategy, Service Planning and Partnering with Consumers, Royal Victorian Eye and Ear Hospital, 32 Gisborne St, East Melbourne, VIC 3002, Australia. ${ }^{3}$ Community Services Workforce Innovation and Integration Lead, Western Health, 176 Furlong Road, St Albans, VIC 3021, Australia.

Received: 8 April 2014 Accepted: 6 September 2014

Published: 13 September 2014

\section{References}

1. Volland PJ, Schraeder Cl, Shelton P, Hess I: The transitional care and comprehensive care coordination debate. J Am Soc Aging 2012, 36:13-19.

2. Banfield M, Gardner K, McRae I, Gillespie J, Wells R, Yen L: Unlocking information for coordination of care in Australia: a qualitative study of information continuity in four primary health care models. BMC Fam Pract 2013, 14:1-11.

3. Schultz EM, Pineda N, Lonhart J, Davies SM, McDonald KM: A systematic review of the care coordination measurement landscape. BMC Health Serv Res 2013, 13:1-12.

4. Berry LL, Rock BL, Houskamp B: Care coordination for patients with complex health profiles in inpatient and outpatient settings. Mayo Clin Proc 2013, 88:84-194.

5. Cipriano P: The imperative for patient, family, and population-centered interprofessional approaches to care coordination and transitional care: a policy brief by the American Academy of Nursing's Care Coordination Task Force. Nurs Outlook 2012, 60:330-333.

6. Seddon D, Krayer A, Robinson C, Woods B, Tommis Y: Care coordination: translating policy into practice for older people. Qual Ageing 2013, 14:81-92.

7. Van Houdt S, Heyrman J, Vanhaecht K, Sermeus W, De Lepeleire J: An in-depth analysis of theoretical frameworks for the study of care coordination. Int J Integrated Care 2013, 13:1-8.

8. Social Work Leadership Institute: Toward the Development of Care Coordination Standards. An Analysis of Care Coordination in Programs for Older Adults. [http://www.nyam.org/social-work-leadership-institute/ docs/care-coordination/N3C-NYS-DOH-SOFA-Care-Coordination-Report-plusnew-york.pdf]

9. Naccarella L, Freijser L: Evaluation of Models of Care Coordination Funded by Divisions of General Practice. 2012, [http://www.gpnsw.com.au/_data/ assets/aboriginalhealth/20120822_CCEvalFINALREPORT_fin.pdf]

10. Gardner K, Yen L, Banfield M, Gillespie J, Mcrae I, Wells R: From coordinated care trials to Medicare locals: what difference does changing the policy driver from efficiency to quality make for coordinating care? Int I Qual Health Care 2013, 25:50-57.

11. Banfield MA, Gardner KL, Yen LE, McRae IS, Gillespie JA, Wells RW: Coordination of care in Australian mental health policy. Aust Health Rev 2012, 36:153-157. 
12. Council of Australian Governments: National Health Reform Agreement. 2011, [https:/www.coag.gov.au/node/96]

13. Independent Hospital Pricing Authority: Tier 2 Non-admitted Services Compendium 2013-2014. [http://www.ihpa.gov.au/internet/ihpa/ publishing.nsf/Content/tier2-non-admit-services-compendium-2013-14]

14. Chen LM, Ayanian JZ: Care continuity and care coordination: what counts? JAMA Intern Med 2014, 174:749-750.

15. Bird SR, Kurowski W, Dickman GK, Kronborg I: Integrated care facilitation for older patients with complex health care needs reduces hospital demand. Aust Health Rev 2007, 31:451-461.

16. Leu JD, Huang YT: An application of business process method to the clinical efficiency of hospital. J Med Syst 2011, 35:409-421.

17. Davenport TH, Short JE: The new industrial engineer: information technology and business process redesign. Sloan Manage Review 1990, 11-27. CISR WP No.213 WP No. 3190-3190.

18. Unertl KM, Novak LL, Johnson KB, Lorenzi NM: Traversing the many paths of workflow research: developing a conceptual framework of workflow terminology through a systematic literature review. J Am Med Inform Assoc 2010, 17:265-273.

19. Qian SY, Yu P, Zhang ZY, Hailey DM, Davy PJ, Nelson MI: The work pattern of personal care workers in two Australian nursing homes: a time-motion study. BMC Health Serv Res 2012, 12:305.

20. Milosavljevic M, Williams P, Perez G, Dalla T: The results of a pilot timeand-motion study in three Australian hospitals: Where do we spend our time? Nutr Diet 2011, 68:185-188

21. Anderson D, St Hilaire D, Flinter M: Primary care nursing role and care coordination: An observational study of nursing work in a community health centre. Online J Issues Nurs 2012, 17:3.

22. Dgedge M, Mendoza A, Necochea E, Bossemeyer D, Rajabo M, Fullerton J: Assessment of the nursing skill mix in Mozambique using a task analysis methodology. Hum Resour Health 2014, 12:5.

23. Stevenson L, Parent K, Purkis ME: Redesigning care delivery in British Columbia. Healthc Manage Forum 2012, 25:16-19.

24. Department of Transport, Planning and Local Infrastructure: Victoria in Future 2012. The Victorian Government's official population and household projections. [http://www.dpcd.vic.gov.au/home/publications-andresearch/urban-and-regional-research/census-2011/victoria-in-future-2012]

25. Djerriwarrh Health Services Better: Health Plan for the West. 2012, [djhs. com.au/fileadmin/.../BHPFTW_13_FINAL_JUNE_2012.pdf]

26. Rich E, Lipson D, Libersky J, Parchman M: Coordinating Care for Adults with Complex Care Needs in the Patient-Centered Medical Home: Challenges and Solutions, White Paper (Prepared by Mathematica Policy Research under Contract No. HHSA2902009000191/HHSA29032005T). AHRQ Publication No. 12-0010-EF. Rockville, MD: Agency for Healthcare Research and Quality; 2012

27. Haas S, Swan BA, Haynes T: Competencies for care coordination and transition management. Nurs Econ 2013, 31:44-49.

28. McDonald KM, Schultz E, Albin L, Pineda N, Lonhart J, Sundaram V, Smith-Spangler C, Brustrom J, Malcolm E: Care Coordination Measures Atlas. Rockville, MD: Agency for Healthcare Research and Quality; 2011 [http://archive.ahrq.gov/professionals/systems/long-term-care/resources/ coordination/atlas/index.html]

29. Ehrlich C, Kendall E, Muenchberger H: Spanning boundaries and creating strong patient relationships to coordinate care are strategies used by experienced chronic condition care coordinators. Contemp Nurs 2012, 42:67-75.

30. Hartgerink JM, Cramm JM, Bakker TJ, van Eijsden RA, Mackenbach JP, Nieboer AP: The importance of relational coordination for integrated care delivery to older patients in the hospital. J Nurs Manage 2014, 22:248-256.

31. Independent Hospital Pricing Authority (IHPA): National Efficient Price Determination 2014-2015. 2014 [http://www.ihpa.gov.au/internet/ihpa/ publishing.nsf/Content/nep-determination-2014-15-html inscope-phservices non-admitted-services]

doi:10.1186/1478-4491-12-52

Cite this article as: Heslop et al:: Building workforce capacity for complex care coordination: a function analysis of workflow activity. Human Resources for Health 2014 12:52.

\section{Submit your next manuscript to BioMed Central and take full advantage of:}

- Convenient online submission

- Thorough peer review

- No space constraints or color figure charges

- Immediate publication on acceptance

- Inclusion in PubMed, CAS, Scopus and Google Scholar

- Research which is freely available for redistribution 